\title{
Out with the old: Inhibition of old items in a preview search is limited
}

\author{
Stephen M. Emrich, Justin D. N. Ruppel, Naseem Al-Aidroos, And Jay Pratt \\ University of Toronto, Toronto, Ontario, Canada
}

AND

SusAnNe Ferber

University of Toronto, Toronto, Ontario, Canada

and Rotman Research Institute, Baycrest, Toronto, Ontario, Canada

\begin{abstract}
If some of the distractors in a visual search task are previewed prior to the presentation of the remaining distractors and the target, search time is reduced relative to when all of the items are displayed simultaneously. Here, we tested whether the ability to preferentially search new items during such a preview search is limited. We confirmed previous studies: The proportion of fixations on old items was significantly less than chance. However, the probability of fixating old locations was negatively affected by increasing the number of previewed distractors, suggesting that inhibition is limited to a small number of old items. Furthermore, the ability to inhibit old locations was limited to the first four fixations, indicating that by the fifth fixation, the resources required to sustain inhibition had been depleted. Together, these findings suggest that inhibition of old items in a preview search is a top-down mediated process dependent on capacity-limited cognitive resources.
\end{abstract}

Our sensory environment is complex and dynamic. The bombardment of distracting stimuli encountered in daily life can include swerving taxi cabs, flashing billboards, and crowds of pedestrians, most of which are irrelevant to our current task or goal (e.g., finding a street sign). To help accomplish these goals, the attentional system uses a number of mechanisms to select some items for more detailed cognitive processing. One such mechanism is the ability to prioritize novel information, as previously attended items tend to be inhibited (e.g., Carmi \& Itti, 2006; McCarley, Wang, Kramer, Irwin, \& Peterson, 2003; Posner \& Cohen, 1984).

One demonstration of the ability to prioritize new information comes from the preview search literature (e.g., Watson \& Humphreys, 1997). When a subset of the distractors in a conjunction search task is previewed prior to the presentation of the remaining distractors and the targets, search slopes are substantially reduced relative to those for a search in which all distractors and targets are presented simultaneously. Watson and Humphreys initially proposed that top-down attentional inhibition of the previewed items enables the prioritization of the new items through a process described as visual marking. Accordingly, as cognitive resources are limited, a top-down account of inhibition would predict that the preview effect holds only for a limited number of distractor items. In contrast, if the preview effect were driven purely by bottomup processes, attention should be biased away from old items regardless of the set size. In fact, some models of the preview effect suggest that the prioritization of new objects is critically dependent on bottom-up changes associated with the appearance of these items (Donk \& Theeuwes, 2001, 2003; Pratt, Theeuwes, \& Donk, 2007). According to this model, the preview benefit occurs not as a result of top-down modulated inhibition of the old items but, rather, as a result of the stimulus-driven capture of attention by the new items. In other words, regardless of attentional or memory load, suddenly appearing novel items should always receive prioritized treatment.

Although the finding of a capacity limit to the prioritization of new over old items would support the active inhibition account, evidence for such a limitation has been hard to come by. For example, reaction time benefits have been demonstrated on very large set sizes (e.g., Watson \& Humphreys, 1997), suggesting that there is no capacity limit on the number of items that can be inhibited. More recently, Watson and Inglis (2007) found that the biasing of eye movements away from old items was evident during catch trials even after $5 \mathrm{sec}$, indicating no limitation on the ability to inhibit old items within this time period.

One possible reason for the lack of evidence for a capacity limit may be the use of multicolored sets in many studies of visual marking. Under these conditions, the prioritization of new items may be bolstered by color-based feature inhibition (Braithwaite, Humphreys, \& Hodsoll, 2003 ) in addition to inhibitory mechanisms dependent

S. M. Emrich, steve.emrich $@$ utoronto.ca 
only on the temporal segregation of old and new items (Braithwaite, Humphreys, \& Hulleman, 2005). In fact, Watson and Inglis (2007) found evidence that eye fixations were affected by this type of color-based guidance. Thus, it is possible that the prioritization of new items over previewed items at large set sizes is aided by color-based selection mechanisms, thereby concealing the real capacity limit of inhibition.

In the present study, we examined the patterns of eye fixations during a preview search to determine how the efficiency of prioritization is affected by set size and how the efficiency changes over time. More specifically, in the absence of color-based guidance, does prioritization decrease in efficiency as the number of previewed items increases (supporting the active inhibition account) or are all old items treated equally (supporting the passive capture account)? Furthermore, how does the prioritization of new items express itself throughout the search process? Namely, is this prioritization limited to only the beginning of search, or does it continue indefinitely?

\section{METHOD}

\section{Participants}

Twelve students ( 3 male, 9 female), 21-28 years old ( $M=$ 21.3 years), from the University of Toronto participated in the study. All of the participants were right-handed and had normal or corrected-to-normal vision. Participants received partial course credit or financial payment $(\mathrm{C} \$ 10)$ for participation in the experiment. All procedures were approved by the Review Ethics Board at the University of Toronto.

\section{Apparatus}

Eye movements were recorded by monitoring retinal position and corneal reflectance using a camera-based eyetracker (SR Research EyeLink II) with a temporal resolution of $250 \mathrm{~Hz}$ and a spatial resolution of $0.2^{\circ}$. The beginning and end of saccadic eye movements were determined using a $30 \% \mathrm{sec}$ threshold with the additional criterion that the eye exceed an acceleration of $8,000^{\circ} / \mathrm{sec}$ during the movement. Experimental displays were presented on a 19-in. computer monitor at a distance of $57 \mathrm{~cm}$ from the participant. Displays were presented using a refresh rate of $100 \mathrm{~Hz}$ and a resolution of $1,024 \times 768$ pixels.

\section{Design and Procedure}

Each participant completed the same procedure in the experimental session, which consisted of eyetracker setup, followed by one block of 5 practice trials and seven blocks of 60 experimental trials each. During eyetracker setup, a nine-point calibration was performed and validated repeatedly until a minimum average accuracy of $.4^{\circ}$ was obtained.

Following initial eyetracker setup, participants performed a visual search task that included both a preview and a no-preview condition (see Figure 1). Participants were instructed to search for the target letters "p" or "b" among the distractors "q" and "d," and to report which target was present. All letter stimuli were presented in green on a gray background and subtended $0.8^{\circ}$ of visual angle. Stimuli were arranged randomly on the display, distanced at least $2^{\circ}$ from each other and from the central fixation point that was presented at the start of each trial. If necessary, a recalibration was performed between blocks.

In the preview condition (see Figure 1A), participants were instructed to maintain fixation on a black disk located in the center of the screen. Participants were required to keep their gaze within $1.5^{\circ}$ of the circle for $450 \mathrm{msec}$ without blinking. If participants failed to meet this requirement, a $200-\mathrm{Hz}$ error tone sounded and a driftcorrection display was presented before the trial recommenced. If

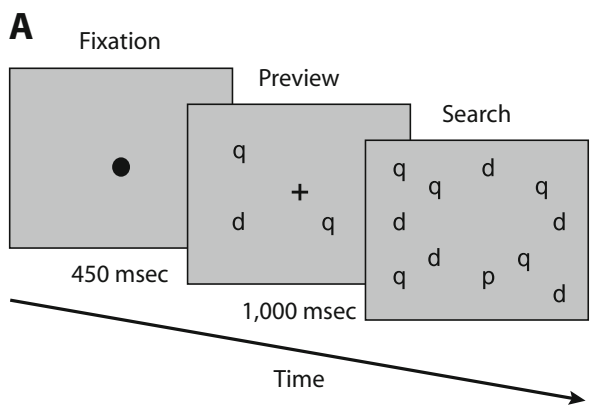

B

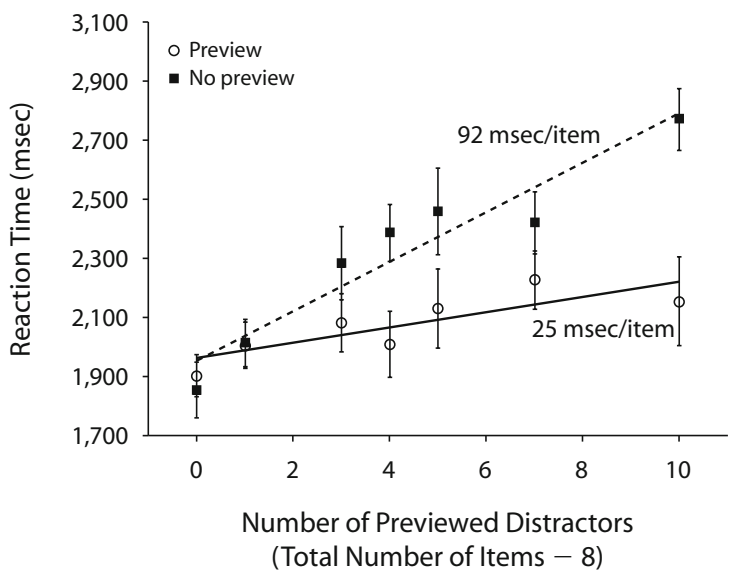

Figure 1. (A) Schematic diagram of a trial in the preview condition. In the preview display, 1-8 distractors could be presented. In the no-preview condition, no items were presented in the preview display, with the same total number of items presented simultaneously in the search display. (B) Mean reaction times (RTs) for the preview (open circle) and no-preview (square) conditions, by the number of previewed distractors. Error bars denote standard errors of the means. Search slopes are indicated.

fixation was maintained, participants were presented with a 1,000 msec preview display of distractor items. The number of previewed items varied among $0,1,3,4,5,7$, and 10 . We presented 30 trials for each set size. During the preview display, the central fixation disk was replaced with a black cross to alert the participants that the previewed items had appeared on the screen. The participants were informed that this initial preview did not contain the target. If eye movements were made during the preview display, the trial was aborted and recycled as a later trial. After 1,000 msec of the preview display, a $1000-\mathrm{Hz}$ "Begin Search" tone sounded, and the fixation cross disappeared, providing a visual and an auditory cue for the participant to begin the search task. As this tone was emitted, eight novel stimuli (including the target) were presented in addition to the previewed items, and the participants were allowed to begin to search for the target. The participants indicated with one of two button responses on a controller pad whether the target was the letter "p" or "b." Auditory feedback was presented if the participants responded incorrectly. Following the response, a gray display screen was presented for $500 \mathrm{msec}$, and then the next trial began.

Trials in the no-preview condition followed a similar procedure, except that there was no preview display, and all items were presented together after the $1000-\mathrm{Hz}$ "Begin Search" tone. Thus, the total number of items in the final search displays was equivalent in the preview and the no-preview conditions. The preview and nopreview trials were randomly intermixed within each block. 


\section{Measures}

In addition to measuring reaction times (RTs) to the target response, we measured the propensity for individuals to look at the old previewed distractors during the search process. In order to determine what items participants were looking at, the Euclidean distance between the end location of each saccade and all search items was calculated, and the closest item was deemed to be the gazed-at item. Each saccade was further classified as having reoriented gaze to an old distractor, a new distractor, or the target. Thus, for each fixation, the total proportion of fixations on old, new, and target items was equal to one. In the no-preview condition, a number of the distractors corresponding to a preview condition were deemed "old," although these items were presented simultaneously with the rest of the distractors and target.

Since participants were told that the target would not appear in the previewed items, we defined an inefficient search as one in which participants searched new and old distractors indiscriminately. If participants were searching items at random, the probability of looking at old or new items would be proportional to the total number of items. Therefore, the expected probability of searching an old item by chance alone can be defined $p=o / s$, where $p$ is the probability of searching an old distractor, $o$ is the number of items previewed, and $s$ is the total set size (old and new distractors plus the target). Accordingly, should the proportion of fixations at old locations be significantly smaller than chance would predict, this would suggest an ability to inhibit old locations.

In order to assess how the biasing of eye movements is expressed over time, we examined the change in the proportion of fixations at old locations over the first five saccades. In addition, by examining a range of set sizes of previewed items between 0 and 10 , we examined how the inhibition of old items is affected by set size. If the ability to inhibit old items is a limitless process, the proportions of fixations on old items should not be affected by set size.

\section{RESULTS}

Data sets of 2 participants were removed because their eyes could not be tracked accurately, resulting in 10 participants for the data analysis.

\section{Errors}

Participants made incorrect responses on an average of $2.5 \%$ and $1.9 \%$ of the preview and no-preview trials, respectively, with no significant difference between conditions.

\section{Reaction Time}

The RT data from correct response trials in both the preview and no-preview conditions are displayed in Figure 1 B. A full 2 (preview vs. no-preview) $\times 7$ (set size) repeated measures ANOVA revealed a significant effect of preview condition on reaction time $[F(1,9)=57.82$, $\left.M S_{\mathrm{e}}=2,002,868.06, p<.001\right]$. The main effect of set size was significant $\left[F(6,54)=19.127, M S_{\mathrm{e}}=775,047.07\right.$, $p<.001]$, as was the interaction between the number of previewed items and preview condition $[F(6,54)=7.562$, $\left.M S_{\mathrm{e}}=257,629.91, p<.001\right]$, demonstrating the established preview benefit in search RT (Figure 1B).

\section{Proportion of Fixations to Old Locations}

In order to determine the presence of a preview effect in the pattern of fixations to old locations, a full ANOVA was performed incorporating both the preview and nopreview conditions. An example of the difference in fixations between the preview and no-preview conditions is

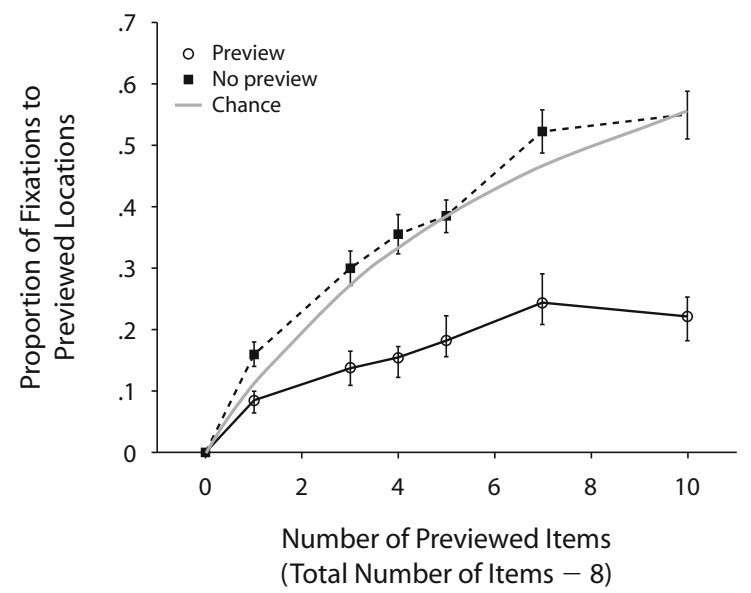

Figure 2. The proportion of first fixations to previewed locations for both the preview (open circle) and no-preview (square) conditions by the number of previewed items. The solid gray line indicates chance performance, defined by the ratio of previewed items to total set size. Error bars denote standard errors of the means.

presented in Figure 2 for the first fixation made on each trial. The full repeated measures ANOVA revealed significant main effects of preview condition $[F(1,9)=9.40$, $\left.M S_{\mathrm{e}}=0.954, p<.05\right]$, set size $\left[F(6,54)=161.78, M S_{\mathrm{e}}=\right.$ $2.682, p<.001]$, and fixation number $[F(4,36)=19.51$, $\left.M S_{\mathrm{e}}=0.196, p<.001\right]$. All interactions were significant at the $p<.001$ level. Thus, in the preview condition, eye fixations were biased away from old items, confirming that our paradigm resulted in a reliable preview effect.

The two questions of interest for this study pertain to the effects of set size and fixation number on the efficiency of inhibiting old locations. Accordingly, we conducted an additional $5 \times 7$ repeated measures ANOVA on the proportion of fixations to old locations examining only the preview condition. The proportions of fixations on old items for all five fixations are presented in Figure 3 . Both set size and fixation number demonstrated significant main effects $\left[F(6,54)=50.43, M S_{\mathrm{e}}=0.935\right.$, $p<.001$, and $F(4,36)=39.68, M S_{\mathrm{e}}=0.322, p<.001$, respectively]. This demonstrates that the ability to inhibit old locations is affected both by the number of previewed items and by the number of fixations made. The interaction between set size and fixation number was also significant $\left[F(24,216)=4.45, M S_{\mathrm{e}}=0.024, p<.001\right]$. These findings suggest that the inhibition afforded by the preview search is not a limitless effect, whether in terms of the length of time that inhibition can occur or in terms of the number of items that can be effectively inhibited.

As can be seen from Figure 3, not only does the efficiency of inhibition change with fixation number, but the ability to inhibit old locations disappears entirely after the fourth fixation, as the proportion of fixations to old locations approaches chance levels by the fifth fixation. To test this effect, mean facilitation scores (collapsed across set size) were calculated by subtracting the obtained proportions of fixations on old items from the probability of 


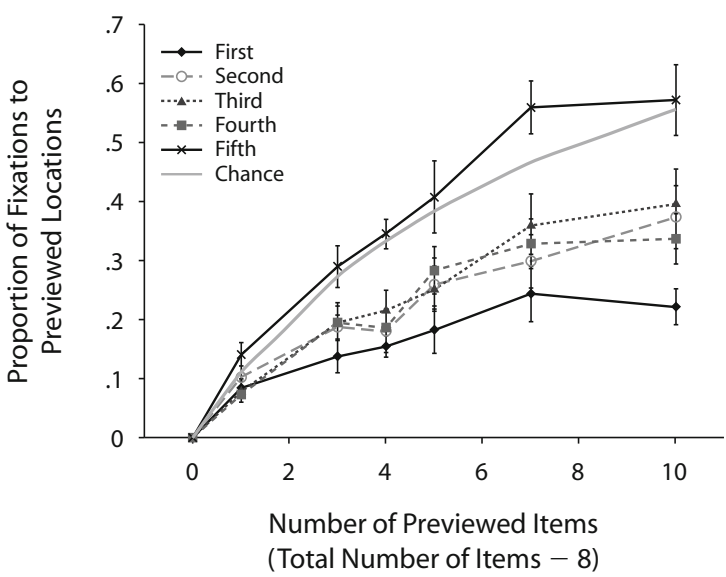

Figure 3. The proportion of fixations in the preview condition to previewed locations by the number of previewed items. Data are plotted separately for the first five fixations of each trial. The solid gray line indicates chance performance. Error bars denote standard errors of the means.

fixating old items by chance. The mean facilitation score, therefore, assessed whether the probability of selecting an old location differed from chance levels at each of the five fixations, where negative values indicate inhibition (old items were fixated at proportions less than chance). Five two-tailed, one-sample $t$ tests confirmed that these facilitation scores were significantly different from zero for the first four fixations at the $p<.01$ levels (Holm's test corrected), but not for the fifth saccade (see Table 1 for $t$ and $p$ values). Therefore, in the preview condition, participants searched the old items significantly less than chance would predict, but only for the first four fixations.

It is possible that participants searched multiple items with each fixation, because typical searches produce search slopes of less than one fixation per item (Zelinsky \& Sheinberg, 1997). Consequently, an exhaustive search of all the new items could be completed in four fixations or fewer, thereby accounting for the apparent limitation. To test for this potential confound, we examined the second and third nearest items to the current center of fixation, to determine whether participants were searching multiple old items on the first four fixations. If participants actually do process more than one item per fixation, we would expect them to fixate regions with multiple new items and few old items. In other words, we should see a preview effect (a decrease in the proportion of fixations on old items)

Table 1

Mean Facilitation Scores and $t$ Values

\begin{tabular}{lccc}
\hline \multicolumn{4}{c}{ Mean Facilitation Scores and $t$ Values } \\
\cline { 2 - 4 } Fixation & $M$ & $S E$ & $t$ \\
\hline First & .18 & .68 & $8.54^{*}$ \\
Second & .12 & .10 & $3.73^{*}$ \\
Third & .10 & .90 & $3.58^{*}$ \\
Fourth & .12 & .83 & $4.59^{*}$ \\
Fifth & -.03 & .80 & -1.26 \\
\hline
\end{tabular}

${ }^{*} p<.01$. for the second and possibly third nearest items to fixation. In contrast to the item closest to fixation, no preview effect was found for the second or third nearest items; that is, the proportion of old items at these locations was equal to chance, suggesting that participants were searching only a single new item with each fixation.

\section{Relating Number of Fixations and RT}

The observation that participants fixated old items significantly less than chance demonstrates that the observed reduction in RT was related to the biasing of attention away from old items. The question remains, however, to what extent RTs were related to the pattern of fixations, given that the bias away from old items was limited to the first four fixations. In order to test this, the group-averaged RTs for each set size were correlated with the average number of fixations (Figure 4). In the preview condition, the correlation between the mean number of fixations on old items and mean RT across all set sizes was $r=.93$ $(p<.005)$, whereas for the no-preview condition, the correlation was $r=.98(p<.001)$. Thus, fixations on old items have a negative and direct impact on RTs for both conditions; that is, fixating old items increases RTs, making search less efficient. The correlations between average RTs and the average number of fixations on all items, including new, were as highly correlated $(r=.99, p<$ .001 , for both the preview and the no-preview conditions). Thus, the number of eye movements made was directly related to the observed RT at each set size, providing further support for the relationship in the inhibition of saccades toward old items and the observed preview benefit in RT across all set sizes.

\section{DISCUSSION}

In the present study, we measured the pattern of eye movements during a preview search task in order to examine the degree to which prioritization of new information is limited. As expected, we found a preview effect across a large range of set sizes. The pattern of fixations, however, demonstrates that the efficiency of the preview effect is limited in two ways. First, the number of previewed items that are not fixated is limited. In an ideal case, individuals would never search old items, even when the number of previewed items was large, leading to an unchanging probability close to zero. In reality, the proportion of fixations to old locations increases fairly constantly with the number of previewed items (see, e.g., Figure 2). Thus, the ability to inhibit old locations appears to be limited to a small number of items.

The second limitation is that the probability of gazing at a previewed item changes across fixations. Our results demonstrate that whereas the proportion of fixations to old locations is significantly lower than chance for the first four fixations, this is no longer the case by the fifth fixation. Although it is theoretically possible that participants have exhausted a search of all the new items in only four fixations, this possibility seems unlikely given that our results are consistent with a search of one item per fixation. Thus, although our finding that fixations are bi- 


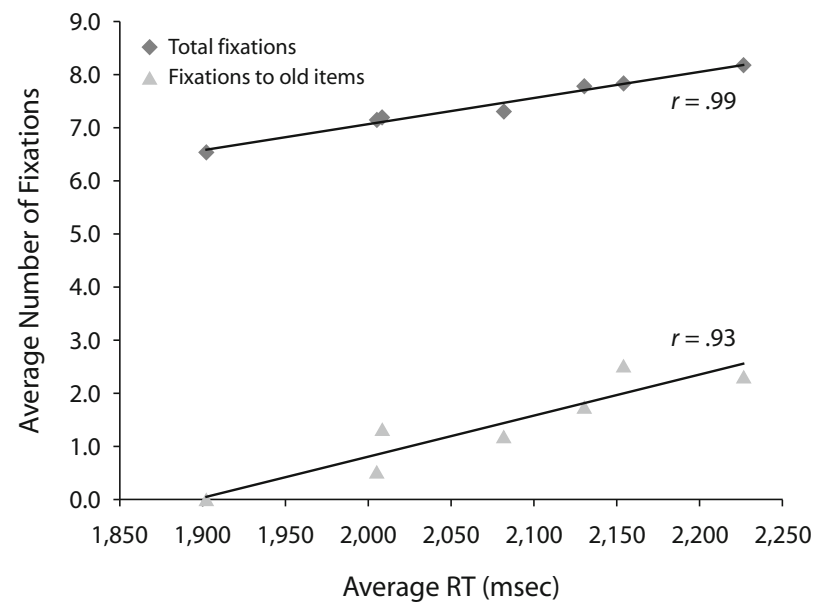

Figure 4. Correlations between average reaction times (RTs) and the average number of fixations on old items (triangles) or total fixations (diamonds) in the preview condition. Each data point corresponds to a preview set size.

ased away from old items confirms the findings of Watson and Inglis (2007), we have demonstrated that this effect does not persist throughout the entire search process.

Our findings provide some insights into the underlying mechanisms of the preview effect. If the preview effect were largely independent of the limits of cognitive processing (i.e., driven by the stimulus properties of the new items alone), there should be few if any limitations on the ability to prioritize new information. Top-down inhibition, however, should be limited by cognitive resources, and thus our finding that the preview effect is in fact limited to a small number of items and fixations largely supports an active inhibition account of the preview effect. One possible counterexplanation is that participants are simply switching strategies after the first four fixations. Participants know, however, that the target can never appear in the previewed items, and thus, inhibiting old items (even only a few) is always an efficient strategy to employ, even after one has exhaustively searched the new items. Interestingly, although priority for the new items was limited to the first four fixations, the search slope appeared to remain constant, even at large set sizes. Thus, our results suggest that the preview benefit for RTs may be fairly constant across a large range of set sizes, even though the reduction in RT may result entirely from the ability to preferentially select new items during the first few fixations only.

What precisely are the cognitive processes that limit the active inhibition of old items? Although fixations are, in general, biased away from old items, this bias lasts only through the course of the first few fixations. It is unlikely that this limit occurs simply because of the passage of time, for previous studies have demonstrated that it is more difficult to detect the presence of a probe at the locations of previewed items $1,200 \mathrm{msec}$ after the onset of the preview display than it is after only $800 \mathrm{msec}$ (Humphreys, Stalmann, \& Olivers, 2004). In contrast, the reduced inhibitory effect may be related to the execution of eye movements as individuals perform the search for the target.

How does executing a saccade affect the inhibition of previewed items? Evidently, inhibition survives beyond the first saccade and, therefore, cannot be guided by retinotopic coordinates. An alternative process is more directly linked to the apparent limit in the number of previewed items that can be inhibited. We argue that the ability to inhibit previewed items may be dependent on some capacity-limited resource and that as each fixation is made at a new location, the new item competes with the resources representing the previewed items. This competition would diminish the ability to inhibit old locations successfully until the new items absorbed all the available resources required for inhibition. The results of the present study would therefore suggest that after the fourth fixation, all of the resources necessary for inhibition had been purged. Given the evidence that participants are searching a single item with each fixation, this would suggest that inhibition is abolished after searching just four items. Support for this conclusion comes from McCarley et al. (2003), who demonstrated that when presented with two items in a serial-search task - one previously fixated item and one new item - participants were more likely to search the new location only if the old item had appeared within the last four fixations; after four fixations, participants revisited the old location with chance performance. Interestingly, this capacity limit corresponds to the capacity of visual short-term memory (Cowan, 2001; Luck \& Vogel, 1997). In fact, previous studies have found that the preview benefit is greatest when the number of previewed items is within this capacity (Jiang, Chun, \& Marks, 2002), providing evidence that this effect may depend in part on this sort of memory store (but see Jiang \& Wang, 2004). Regardless of whether this effect is dependent on memory processes, the findings that the preview effect is affected by the number of previewed items and by 
the number of executed eye movements suggest that the preview effect cannot be driven by the stimulus properties alone but may, instead, be dependent on general capacitylimited resources.

\section{AUTHOR NOTE}

This research was supported by NSERC grants to S.F. and J.P. NSERC scholarships to N.A. and S.M.E., and a CIHR grant awarded to S.F. The authors thank Derrick Watson and Jason Braithwaite for helpful comments. Correspondence concerning this article should be addressed to S. M. Emrich, Department of Psychology, University of Toronto, 100 St. George Street, Toronto, ON, M5S 3G3 Canada (e-mail: steve .emrich@utoronto.ca).

Note-Accepted by the editorial board of Editor-Elect Jeremy M. Wolfe.

\section{REFERENCES}

Braithwaite, J. J., Humphreys, G. W., \& Hodsoll, J. (2003). Color grouping in space and time: Evidence from negative color-based carryover effects in preview search. Journal of Experimental Psychology: Human Perception \& Performance, 29, 758-778.

Braithwaite, J. J., Humphreys, G. W., \& Hulleman, J. (2005). Colorbased grouping and inhibition in visual search: Evidence from a probe detection analysis of preview search. Perception \& Psychophysics, 67, 81-101.

CARMI, R., \& ITTI, L. (2006). The role of memory in guiding attention during natural vision. Journal of Vision, 6, 898-914.

Cowan, N. (2001). The magical number 4 in short-term memory: A reconsideration of mental storage capacity. Behavioral \& Brain Sciences, 24, 87-114.

Donk, M., \& Theeuwes, J. (2001). Visual marking beside the mark: Prioritizing selection by abrupt onsets. Perception \& Psychophysics, 63, 891-900.
Donk, M., \& Theeuwes, J. (2003). Prioritizing selection of new elements: Bottom-up versus top-down control. Perception \& Psychophysics, 65, 1231-1242.

Humphreys, G. W., Stalmann, B. J., \& Olivers, C. (2004). An analysis of the time course of attention in preview search. Perception \& Psychophysics, 66, 713-730.

Jiang, Y., Chun, M. M., \& Marks, L. E. (2002). Visual marking: Dissociating effects of new and old set size. Journal of Experimental Psychology: Learning, Memory, \& Cognition, 28, 293-302.

JiANG, Y., \& WANG, S. W. (2004). What kind of memory supports visual marking? Journal of Experimental Psychology: Human Perception \& Performance, 30, 79-91.

LucK, S. J., \& Vogel, E. K. (1997). The capacity of visual working memory for features and conjunctions. Nature, 390, 279-281.

McCarley, J. S., Wang, R. F., Kramer, A. F., Irwin, D. E., \& PeterSON, M. S. (2003). How much memory does oculomotor search have? Psychological Science, 14, 422-426.

PosNer, M. I., \& CoHEN, Y. (1984). Components of visual orienting. In H. Bouma \& D. G. Bouwhuis (Eds.), Attention and performance X: Control of language processes (pp. 531-556). Hillsdale, NJ: Erlbaum.

Pratt, J., Theeuwes, J., \& Donk, M. (2007). Offsets and prioritizing the selection of new elements in search displays: More evidence for attentional capture in the preview effect. Visual Cognition, 15, 133-148.

Watson, D. G., \& HuMPhREYs, G. W. (1997). Visual marking: Prioritizing selection for new objects by top-down attentional inhibition of old objects. Psychological Review, 104, 90-122.

Watson, D. G., \& INGLis, M. (2007). Eye movements and time-based selection: Where do the eyes go in preview search? Psychonomic Bulletin \& Review, 14, 852-857.

Zelinsky, G. J., \& Sheinberg, D. L. (1997). Eye movements during parallel-serial visual search. Journal of Experimental Psychology: Human Perception \& Performance, 23, 244-262.

(Manuscript received April 1, 2008; revision accepted for publication June 16, 2008.) 